\title{
Short communication: Condition of male dairy calves at auction markets
}

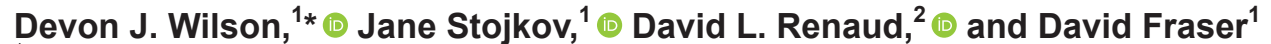 \\ ${ }^{1}$ Animal Welfare Program, University of British Columbia, Vancouver, British Columbia V6T 1ZA, Canada \\ ${ }^{2}$ Department of Population Medicine, University of Guelph, Guelph, Ontario N1G 2W1, Canada
}

\section{ABSTRACT}

Male dairy calves in North America are frequently marketed through live auctions. Calves have been observed in suboptimal condition both at auctions and upon arrival at calf-rearing facilities that supply the veal or dairy-beef industries. The objectives of this study were to describe the health of male dairy calves at a commercial auction in British Columbia, Canada, examine the relationships between calf price and condition, and use price data from other auctions to reflect more broadly on the variability in calf condition at auction markets. Price and breed were recorded for 1,624 male calves, and a sample of 355 calves was assessed using a standardized health exam and body weight estimation. Linear regression was used to assess which calf characteristics were associated with price. Prices for young dairy calves at auctions in 2 other provinces (Nova Scotia and Quebec) were compiled for comparison. Twenty percent of calves had at least one health abnormality; the most common was navel disease $(12 \%)$, followed by ocular or nasal discharge (4\%), a depressed (dull, unable, or unwilling to rise) attitude $(2 \%)$, coughing $(2 \%)$, and joint inflammation $(1 \%)$. The mean $( \pm \mathrm{SD})$ estimated body weight was 47 $\pm 8 \mathrm{~kg}$ with a range of 27 to $82 \mathrm{~kg}$. Calves were sold for up to Can $\$ 370$ (median Can $\$ 140$ ), but $10.5 \%$ sold for Can $\$ 10$ or less, and $2.8 \%$ were not sold at all. [The mean exchange rate over the course of this study (Oct. 2017 to Mar. 2018) was Can $\$ 1=$ US $\$ 0.79$.] Calves with a depressed attitude sold for lower prices than bright, alert calves. In addition, those with Brown Swiss or Jersey genetics sold for lower prices than those with Holstein genetics, and cross-bred calves with beef genetics sold for higher prices. During 2018, $62 \%$ of young dairy calves sold at the Nova Scotia auction and $18 \%$ of young Holstein calves sold in Quebec were classed as lower quality and sold for $23 \%$ and $40 \%$, respectively, of the value of higher-quality calves. The results under-

Received November 6, 2019.

Accepted February 25, 2020.

*Corresponding author: devon.wilson@ubc.ca line the need to develop solutions to reduce the risk of marketing calves in poor condition at auction markets. Key words: male dairy calf, calf health, auction market, price

\section{Short Communication}

The marketing of cattle in poor condition at auctions is an acknowledged problem of animal welfare. Recent studies have identified cattle suffering from lameness, thin body condition, and respiratory disease at auction markets (Barham and Troxel, 2007; Van Metre et al., 2009; Moorman et al., 2018). A study of 5 auction markets in Quebec found that $43 \%$ of male dairy calves had at least 1 health abnormality (Marquou et al., 2019). Data on prices paid for calves at commercial auctions are widely available, and low prices reflected in these data may indicate poor condition of the animals being marketed. For example, in Quebec auctions, smaller calves with inflamed joints and other health problems were sold for lower prices (Marquou et al., 2019). Furthermore, Winder et al. (2016) found that calves purchased in Ontario for lower prices tended to have higher subsequent mortality risk at veal farms, likely because of poor condition at the time of sale. Despite the large number of male dairy calves produced and sold in western Canada, no data are available on their health at auction or after transportation to calfrearing facilities.

The objectives of this study were (1) to describe the health and condition of male dairy calves at a live auction in western Canada, (2) to examine the relationships between price and animal condition, and (3) to use price data from other auctions to reflect more broadly the variability in calf condition at auction markets.

Calves from dairy farms were observed every week or every second week at a live auction market in British Columbia, Canada from October 1, 2017, to March 31, 2018. Calves were delivered in the morning by local dairy farmers or transporters, tagged with a penetrating ear tag for visual identification, and housed in a bedded group holding pen. Calves did not have access to forage, milk, or water, and had fence-line contact with cull dairy cattle. At the time of sale (approxi- 
mately noon), calves were most commonly placed in the sale ring alone and a price was determined through live bidding. Once sold, calves were moved to a bedded pen with access to a chute system that included a ramp to load them for transportation. If no bid was placed, a price of $\$ 0$ was recorded and the calf was moved to a separate pen. The fate of these calves could not be followed systematically. Price and breed were recorded by one observer for 1,624 male calves from 18 separate sale dates, with a range of 57 to 131 calves recorded per day. Calf breed was recorded based on phenotypic characteristics, and included the dairy breeds of Holstein, Jersey, and Brown Swiss, as well mixed dairy and beef (Angus or Belgian Blue) genetics.

Calf condition was assessed within $2 \mathrm{~h}$ before the sale and included a standardized health examination determined with the Calf Health Scorer App (University of Wisconsin-Madison, Madison, WI) as described by Renaud et al. (2018a). Briefly, the App allows scoring of symptoms on a 4-point scale related to respiratory disease (McGuirk and Peek, 2014), diarrhea (Larson et al., 1977), and navel and joint inflammation (Fecteau et al., 1997). At the request of auction management, the assessment did not include rectal temperature or diarrhea scoring, and ear score was not recorded because the recent application of a penetrating ear tag caused some calves to display head shaking and ear drooping. Therefore, measures included attitude, ocular or nasal discharge, cough, and navel and joint inflammation. Because no weigh scale was available at the auction, calf weight was estimated by heart girth circumference measured just caudal to the elbow joint using a soft measuring tape (The Coburn Company Inc., Whitewater, WI) (Heinrichs et al., 2007; Bond et al., 2015). All assessments were made by one experienced veterinarian (D. J. W.). Protocols for animal assessments and sampling were approved by the University of British Columbia Animal Care Committee (application A16-0336-001).

Because of the time required, calf assessments could be done for only about one-half of the available animals. To avoid bias, calves with either odd- or even-numbered ear tags were selected for assessment on a given day, as decided by coin toss on each of the 18 assessment days. In addition, many calves arrived too shortly before the sale to be available for assessment. In total, 383 male calves were assessed. These included 122 calves that were assessed as a part of a larger study that followed calves from dairy farms to their final destination at calf-rearing facilities.

Descriptive statistics were calculated using Excel (Microsoft Corp., Redmond, WA). Health scores were collapsed into dichotomous variables denoting "normal" for scores 0 and 1 on the various measures recorded on the app, and "abnormal" for scores 2 and 3 . To evaluate intra-observer agreement for health scores, 25 calves at the University of British Columbia's Dairy Education and Research Center were assessed twice on $1 \mathrm{~d}$, approximately $3 \mathrm{~h}$ apart. Weighted (for measures with multiple levels) and unweighted (for binary measures) kappa coefficients were used to determine agreement. Cicchetti-Allison weight type was used for the weighted kappa calculation (Cicchetti and Allison, 1971). Percent agreement ranged from 88 to $100 \%$, which was considered high. Intra-observer agreement for heart girth was calculated by a concordance correlation for 106 calves assessed within $1 \mathrm{~h}$ before transportation, and again approximately $3 \mathrm{~h}$ later at the auction market $(\mathrm{r}=0.95)$. Because price fluctuated over time, a standardized price was calculated following methods from Marquou et al. (2019). Briefly, individual calf price was subtracted from the median price of all calves sold that day.

Complete heart girth and health scores were available for 355 calf assessments. Of the 355 records, there were only 3 Brown Swiss and 4 Jersey calves; these were removed from regression analysis, leaving 348 calves. The effects of breed (cross-bred beef vs. Holstein), health score, and heart girth on standardized price were analyzed using a linear regression model (Proc GLM, SAS University Edition; SAS Institute Inc., Cary, NC) following methods in Dohoo et al. (2003). Variables were assessed individually for association with standardized price, and associated factors $(P<0.2)$ were tested in the multivariable model. Manual backward elimination was used to remove variables with a non-significant association $(P>0.05)$. Breed was retained in the model based on previous work indicating a strong association with price (Marquou et al., 2019), and was significant $(P<0.05)$ once navel score was removed. The resulting model, including heart girth, attitude, and breed, had a lower Akaike information criterion compared with heart girth and attitude alone. Collinearity was assessed between variables in the final model using a Spearman rank correlation with a cutoff value of $>0.6$ and variance inflation factors assessed with a cutoff of $\geq 5$. No collinearity between variables was observed. All pair-wise interactions were evaluated in the final model and none were significant. The model was evaluated visually for normality using a plot of residuals and predicted outcomes. All model building was conducted in SAS University Edition. A separate descriptive analysis of all 1,624 calves was used to compare standardized price for all breeds.

For comparative data from other regions, information about calf prices was collected for the year 2018 from auction markets in Nova Scotia (Altantic Stockyards Limited, 2019) and Quebec (Les Producteurs 
de bovins du Québec, 2019) from each organization's publicly accessible website. The mean weekly prices for "average" versus "good" young dairy calves ("bob calves") were collected from the Atlantic Stockyards. The mean weekly prices for Holstein "low-quality" ("divers") calves compared with "good" or "average" calves were collected from Les Producteurs de Bovins du Québec. These classifications, assigned by auction market staff, are not standardized between auctions, and contain calves of varying weights. Weighted mean weekly price for each calf category was calculated based on the mean weekly price weighted by the number of calves sold that week. Expressed as median and interquartile range, the Atlantic Stockyards sold a median of 47 (36-65) "average" calves and 31 (22-37) "good" calves per weekly sale, and Quebec auctions sold 386 (342-463) "low-quality" calves and 1,771 $(1,683-1,875)$ "good/average" calves.

Calf health at the time of auction was highly variable, with $20 \%$ of calves having at least one abnormality, most often swollen and painful navels (Table 1). Similarly, Marquou et al. (2019) found that omphalitis (swelling, discharge, or pain of the navel) was the most common abnormality, found in $20.3 \%$ of calves at an auction in Quebec. Furthermore, although only 7 calves $(2 \%)$ showed a depressed attitude, some of these calves were in very poor condition and unable to stand. Calves had a mean \pm SD heart girth of $83 \pm 5 \mathrm{~cm}$, corresponding to $47 \pm 8 \mathrm{~kg}$ with a range of 27 to $82 \mathrm{~kg}$ (Heinrichs et al., 1992). Similar results $(47.5 \pm 6.9 \mathrm{~kg})$ were observed in Quebec (Marquou et al., 2019). These findings are concerning because light-weight calves and those with navel disease have reduced growth (Renaud et al., 2018b) and increased mortality (Renaud et al., 2018a) at veal farms. Further effort is required to ensure calves are shipped from dairy farms in robust condition and do not experience challenges during transport and marketing that would cause deterioration in their condition.

The median sale price of all 1,624 calves was Can $\$ 140$ per calf, with an interquartile range of Can $\$ 70$ to $\operatorname{Can} \$ 175$ (Can $\$ 1=$ US\$0.79). The price was not

Table 1. Number and percentage of calves with normal and abnormal health scores from a sample of 355 male calves assessed before sale at a commercial auction in British Columbia, Canada

\begin{tabular}{lccc}
\hline Health score & $\begin{array}{c}\text { Abnormal } \\
\text { (no.) }\end{array}$ & $\begin{array}{c}\text { Normal } \\
\text { (no.) }\end{array}$ & $\begin{array}{c}\text { Abnormal } \\
(\%)\end{array}$ \\
\hline Attitude & 7 & 348 & 2 \\
Ocular/nasal & 14 & 341 & 4 \\
Cough & 8 & 347 & 2 \\
Joint & 4 & 351 & 1 \\
Navel & 43 & 312 & 12 \\
At least one abnormality & 70 & 285 & 20 \\
\hline
\end{tabular}

normally distributed (Shapiro-Wilk test $P<0.001$ ); calves were more frequently sold at specific values (e.g., Can\$150, Can\$200), and the distribution was slightly skewed due to the high percentage of low-value calves (Figure 1). At the time of sale, 46 calves $(2.8 \%)$ were declared "no sales"; including these calves, 171 (10.5\%) calves were sold for Can $\$ 10$ or less. Of the 355 healthassessed calves, 32 sold for $\leq \$ 10$; of these, mean $( \pm \mathrm{SE})$ BW was $35.6 \pm 0.9 \mathrm{~kg}$, and $10(31 \%)$ had at least one health abnormality. The 6 assessed calves that were unsold weighed on average $35.2 \pm 2.3 \mathrm{~kg}$ (vs. $47.5 \pm 0.4$ $\mathrm{kg}$ for other calves), and had a mean $( \pm \mathrm{SE})$ of $0.9 \pm$ 0.4 health abnormalities (vs. $0.2 \pm 0.0$ for other calves). These data indicate that unsold calves were generally small and in poor health.

Regression analysis showed that calf health, genetics, and weight were associated with price. The 7 calves showing depressed attitude sold for less than calves with a bright and alert attitude (Table 2). Depressed attitude is not a clinical diagnosis, but is easily recognizable and has been associated with dehydration, likely reflecting calf systemic health (Pempek et al., 2017). The relationship between heart girth and price was linear, with calves receiving approximately Can $\$ 11$ more for every additional $1 \mathrm{~cm}$ (approximately 1.5 additional kilograms) in heart girth circumference. This was expected, as higher BW has been linked to greater weight gain (Renaud et al., 2018b) and lower mortality (Winder et al., 2016) at veal facilities. Of the 348 assessed calves, the 10 with beef genetics sold for higher prices, likely because beef breeds have higher feed efficiency and produce a more desirable carcass than dairy animals (Campion et al., 2009; Clarke et al., 2009). The full sample of 1,624 male calves included 1,531 Holstein, 27 Jersey, 19 Brown Swiss, and 47 crossbred to a beef breed. Median standardized calf prices for Holstein, Jersey, Brown Swiss, and cross-bred beef calves were Can $\$ 0$, - Can $\$ 110$, - Can $\$ 62$, and Can $\$ 30$, respectively, again showing that higher prices are paid for calves with beef genetics (see also Dal Zotto et al., 2009; Marquou et al., 2019).

Seasonal fluctuations in price were also apparent, although the study was limited to autumn and winter. In British Columbia, the median (interquartile range) calf price was slightly lower in November at Can $\$ 125$ (Can $\$ 45-$ Can $\$ 170$ ) and January at Can $\$ 125$ (Can\$50-Can\$150) compared with October at Can $\$ 160$ (Can\$93-Can\$203), December Can\$150 (Can\$95Can\$185), February Can\$155 (Can\$132-Can\$180), and March at Can $\$ 140$ (Can\$100-Can\$173). Similar seasonality has been previously documented in Eastern Canada's auction markets (Renaud et al., 2017). The observed seasonality could reflect variability in weather and its influence on calf performance, but could also 


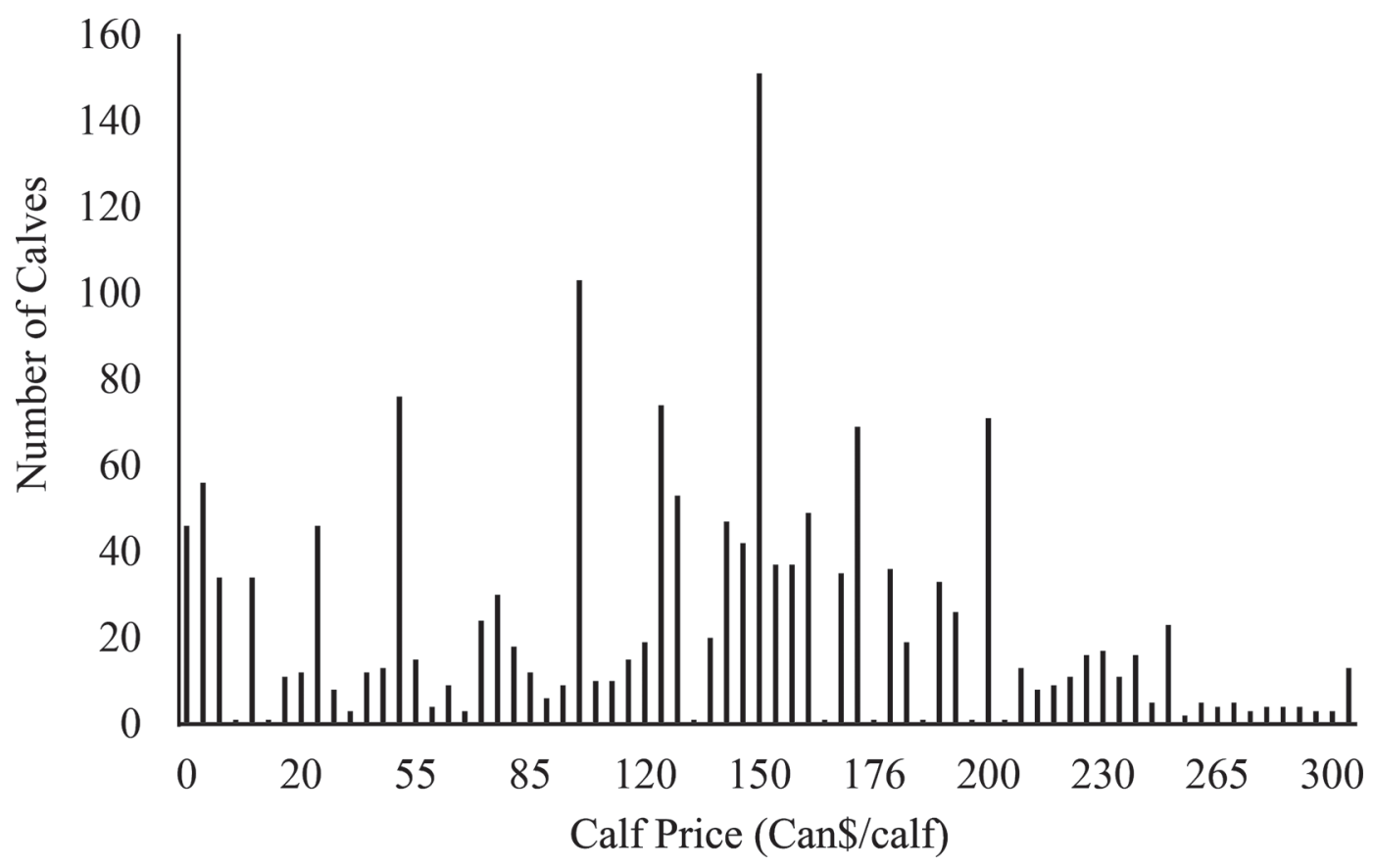

Figure 1. Number of male calves sold for different prices (Can $\$ 1=$ US $\$ 0.79$ at the time of the study) at a commercial auction market from October 1, 2017, to March 31, 2018, in British Columbia, Canada.

relate to fluctuation in feed price, calf inventory, and other market variation, as noted in the beef industry (Twine et al., 2016).

Wide variation in calf quality and price was also observed at other auctions. In Nova Scotia, $62 \%$ of bob calves were marketed as "average" rather than "good" quality and sold for only Can $\$ 36$, compared with Can $\$ 156$ for the "good" calves (Altantic Stockyards Limited, 2019). Similarly, in Quebec, $18 \%$ of Holstein calves were classified as "low-quality" and they sold for Can $\$ 1.07$ per $\mathrm{kg}$ versus Can $\$ 2.70$ per $\mathrm{kg}$ for "good" or "average" calves (Les Producteurs de bovins du Québec, 2019). While these classifications of calves by auction personnel were subjective, they correlated clearly with reduced market value. This suggests that marketing

Table 2. Final linear regression model evaluating the effect of calf condition on standardized price for male dairy calves at a commercial auction in British Columbia, Canada

\begin{tabular}{lrcrc}
\hline Variable & $\mathrm{n}$ & $\begin{array}{c}\text { Coefficient } \\
(\mathrm{Can} \$)\end{array}$ & $\mathrm{SE}$ & $P$-value \\
\hline Intercept & 348 & -894.8 & 39.5 & $<0.0001$ \\
Heart girth & 10.7 & 0.5 & $<0.0001$ \\
Attitude & & & & \\
$\quad$ Alert & 341 & Referent & & \\
$\quad$ Depressed & 7 & -44.6 & 16.4 & 0.007 \\
Breed & 338 & Referent & & \\
$\quad$ Holstein & 10 & 37.1 & 13.6 & 0.007 \\
$\quad$ Beef cross-bred & & & & \\
\hline
\end{tabular}

of poor dairy calves is widespread, even though this practice results in lower sale price at auction.

The results indicate that many dairy calves were sold at a light weight and with health abnormalities that are easily detectable, and some sold for very low prices or did not sell at all. Poor health and light body weight upon arrival at calf-rearing facilities has been related to increased mortality and reduced weight gains in the veal industry (Renaud et al., 2018a,b); hence many calves sold in our study are likely to have reduced productivity and welfare. Our results suggest that guidelines for assessing fitness for transport in calves should include evaluation of attitude, weight, and navel health. Furthermore, these results suggest that dairy farmers could potentially increase their revenue by marketing heavier calves in good health. More investigation is warranted to understand factors contributing to the sale of unhealthy animals and to evaluate strategies to ensure calves are in robust condition when they are marketed.

\section{ACKNOWLEDGMENTS}

We thank the auction that allowed us to conduct this study. We are grateful for the support of our colleagues at the BC Ministry of Agriculture (Abbotsford, BC) who helped in data collection, particularly Jane Pritchard, Terri Giacomazzi, Tom Droppo, Brian Radke, and Erin Cuthbert. This research was supported by the 
BC Ministry of Agriculture through Growing-Forward 2, a federal-provincial-territorial initiative. The University of British Columbia Animal Welfare Program is generously supported by the National Sciences and Engineering Research Council of Canada Industrial Research Chair Program with industry contributions from the Dairy Farmers of Canada (Ottawa, ON, Canada) and many others listed at http://awp.landfood.ubc.ca/ . The authors have not stated any conflicts of interest.

\section{REFERENCES}

Altantic Stockyards Limited. 2019. Weekly Market Reports. Accessed July 22, 2019. https://atlanticstockyards.com/market-reports/.

Barham, B. L., and T. R. Troxel. 2007. Factors affecting the selling price of feeder cattle sold at Arkansas livestock auctions in 2005. J. Anim. Sci. 85:3434-3441. https://doi.org/10.2527/jas.2007-0340.

Bond, G. B., M. A. G. von Keyserlingk, N. Chapinal, E. A. Pajor, and D. M. Weary. 2015. Among farm variation in heifer BW gains. Animal 9:1884-1887. https://doi.org/10.1017/S175173111500097X.

Campion, B., M. G. Keane, D. A. Kenny, and D. P. Berry. 2009. Evaluation of estimated genetic merit for carcass weight in beef cattle: Live weights, feed intake, body measurements, skeletal and muscular scores, and carcass characteristics. Livest. Sci. 126:87-99. https://doi.org/10.1016/j.livsci.2009.06.004.

Cicchetti, D. V., and T. Allison. 1971. A new procedure for assessing reliability of scoring EEG sleep recordings. Am. J. EEG Technol. 11:101-110. https://doi.org/10.1080/00029238.1971.11080840.

Clarke, A. M., M. J. Drennan, M. McGee, D. A. Kenny, R. D. Evans, and D. P. Berry. 2009. Intake, live animal scores/measurements and carcass composition and value of late-maturing beef and dairy breeds. Livest. Sci. 126:57-68. https://doi.org/10.1016/j.livsci 2009.05.017.

Dal Zotto, R., M. Penasa, M. De Marchi, M. Cassandro, N. López-Villalobos, and G. Bittante. 2009. Use of crossbreeding with beef bulls in dairy herds: Effect on age, body weight, price, and market value of calves sold at livestock auctions. J. Anim. Sci. 87:3053-3059. https://doi.org/10.2527/jas.2008-1620.

Dohoo, I. R., W. Martin, and H. Stryhn. 2003. Veterinary Epidemiologic Research. AVC Inc., Charlottetown, PEI, Canada.

Fecteau, G., J. Pare, D. C. Van Metre, B. P. Smith, C. A. Holmberg, W. Guterbock, and S. Jang. 1997. Use of a clinical sepsis score for predicting bacteremia in neonatal dairy calves on a calf rearing farm. Can. Vet. J. 38:101-104.

Heinrichs, A. J., H. N. Erb, G. W. Rogers, J. B. Cooper, and C. M. Jones. 2007. Variability in Holstein heifer heart-girth measurements and comparison of prediction equations for live weight. Prev. Vet. Med. 78:333-338. https://doi.org/10.1016/j.prevetmed 2006.11.002.

Heinrichs, A. J., G. W. Rogers, and J. B. Cooper. 1992. Predicting body weight and wither height in Holstein heifers using body measurements. J. Dairy Sci. 75:3576-3581. https://doi.org/10.3168/ jds.S0022-0302(92)78134-X.

Larson, L. L., F. G. Owen, J. L. Albright, R. D. Appleman, R. C. Lamb, and L. D. Muller. 1977. Guidelines toward more uniformity in measuring and reporting calf experimental data. J. Dairy Sci. 60:989-991. https://doi.org/10.3168/jds.S0022-0302(77)83975-1.

Les Producteurs de bovins du Québec. 2019. Price-Info: Cull Cattle and Bob Calves. Accessed July 21, 2019. http://bovin.qc.ca/en/ price-info/cull-cattle-and-bob-calves/daily/.

Marquou, S., L. Blouin, H. Djakite, R. Laplante, and S. Buczinski. 2019. Health parameters and their association with price in young calves sold at auction for veal operations in Québec, Canada. J. Dairy Sci. 102:6454-6465. https://doi.org/10.3168/jds.2018-16051.

McGuirk, S. M., and S. F. Peek. 2014. Timely diagnosis of dairy calf respiratory disease using a standardized scoring system. Anim. Health Res. Rev. 15:145-147. https://doi.org/10.1017/ S1466252314000267.

Moorman, A. K. G., T. F. Duffield, M. A. Godkin, D. F. Kelton, J Rau, and D. B. Haley. 2018. Associations between the general condition of culled dairy cows and selling price at Ontario auction markets. J. Dairy Sci. 101:10580-10588. https://doi.org/10.3168/ jds.2018-14519.

Pempek, J., D. Trearchis, M. Masterson, G. Habing, and K. Proudfoot. 2017. Veal calf health on the day of arrival at growers in Ohio. J. Anim. Sci. 95:3863-3872. https://doi.org/10.2527/jas2017 1642.

Renaud, D. L., T. F. Duffield, S. J. LeBlanc, D. B. Haley, and D. F. Kelton. 2017. Management practices for male calves on Canadian dairy farms. J. Dairy Sci. 100:6862-6871. https://doi.org/10.3168/ jds.2017-12750.

Renaud, D. L., T. F. Duffield, S. J. LeBlanc, D. B. Haley, and D. F. Kelton. 2018a. Clinical and metabolic indicators associated with early mortality at a milk-fed veal facility: A prospective case-control study. J. Dairy Sci. 101:2669-2678. https://doi.org/10.3168/ jds.2017-14042.

Renaud, D. L., M. W. Overton, D. F. Kelton, S. J. LeBlanc, K. C. Dhuyvetter, and T. F. Duffield. 2018b. Effect of health status evaluated at arrival on growth in milk-fed veal calves: A prospective single cohort study. J. Dairy Sci. 101:10383-10390. https://doi .org/10.3168/jds.2018-14960.

Twine, E. E., J. Rude, and J. Unterschultz. 2016. Canadian cattle cycles and market shocks. Can. J. Agric. Econ. 64:119-146. https: //doi.org/10.1111/cjag.12066.

Van Metre, D. C., D. Q. Barkey, M. D. Salman, and P. S. Morley. 2009. Development of a syndromic surveillance system for detection of disease among livestock entering an auction market. J. Am. Vet. Med. Assoc. 234:658-664. https://doi.org/10.2460/javma.234 .5 .658 .

Winder, C. B., D. F. Kelton, and T. F. Duffield. 2016. Mortality risk factors for calves entering a multi-location white veal farm in Ontario, Canada. J. Dairy Sci. 99:10174-10181. https://doi.org/10 $.3168 /$ jds.2016-11345.

\section{ORCIDS}

Devon J. Wilson (® https://orcid.org/0000-0001-8027-7998

Jane Stojkov @ https://orcid.org/0000-0002-0806-2391

David L. Renaud ๑ https://orcid.org/0000-0002-3439-3987 